\title{
Case Study into the Effect of Intensive Mass Training on Chronic Pure Alexia
} Inge L. Wilms*

Department of Psychology, University of Copenhagen \& Center for Rehabilitation of Brain Injury, Denmark

*Corresponding author: Inge Wilms, Brain Rehabilitation and Advanced Technology, Laboratory, Department of Psychology University of Copenhagen, Øster Farimagsgade 2A, 1353 Copenhagen K, Denmark, Tel: +453532 48 66, +45 405817 16, Fax: +45 353248 02; E-mail: inge.wilms@psy.ku.dk

Rec date: Jan 08, 2015; Acc date: May 27 2015; Pub date: June 03, 2015

Copyright: $\odot 2015$ Wilms I L. This is an open-access article distributed under the terms of the Creative Commons Attribution License, which permits unrestricted use, distribution, and reproduction in any medium, provided the original author and source are credited.

\section{Abstract}

Background Pure alexia is often regarded as a minor deficit when compared to other effects of brain injury. However, the loss of the ability to read is to many a true loss of quality of life.

Objective The study is an explorative case study investigating the effects of intensive reading training in a patient with acquired pure alexia disorder. The training targeted the various stages of the basic reading process.

Methods A patient diagnosed with pure alexia trained for 2 hours a day for 15 days. The training consisted of exposure to word, non-words, sentences and text with varying complexity in format as well as content. The training material was developed to accommodate intensive and adaptive training directed at regaining fundamental reading abilities without the use of compensatory techniques.

Results The patient improved on reading speed for short words, short sentences and text. The patients improved significantly in letter reading speed. There was no significant change in the performance on 3, 5 or 7 letter words before and after training.

Conclusion The case is a prototype study and indicative that intensive may improve reading speed but has no effect on the fundamental problem of word length effect in alexia.

Keywords: Intensive Training; Pure Alexia; Mass Training; Background

\section{Cognitive Rehabilitation}

\section{Introduction}

In terms of rehabilitation efforts, pure alexia has been very resistant to training and the ability to read fluently again is rarely restored in full. Repeated reading of words and sentences also named Multiple Oral Rereading [1,2] has been demonstrated to provide some improvement but others have found no effect $[3,4]$.

This study is an exploratory case study into the effect of highly intensive and adaptive training for letter- and word-reading in a patient diagnosed with pure alexia. The training that was developed as part of the study was inspired by the intensive training conducted with aphasic patients, the so-called Constraint-induced Language Training (CILT). CILT training is a combination of targeted, intensive, personal goal-oriented training in which the patient is gently coerced into using the affected cognitive function to solve more and more challenging tasks $[5,6]$. The intension is to create a use-dependent or focused cortical reorganization to improve the impaired function and overcome learned non-use, a mal-adjustment happening during the early stages of recovery [7]. An important element of cognitive CILT is that the personalized intensive training must challenge the patient gradually with progressively harder tasks [6].

Based on the outcome, the study will be used to determine if there are grounds for a larger and perhaps computer-based study including more subjects.

\section{Pure alexia}

Pure alexia is a disorder arising from brain injury that specifically affects the reading ability of the patient [8]. In pure alexia, the reading speed is severely impacted even though other language abilities including comprehension, writing and spoken language are intact. To the observer, reading is reduced from being fluent and effortless to being a very cumbersome letter-by-letter process. Pure alexia is for that reason often referred to as letter-by-letter reading although it has been argued that the stepwise letter-reading may be regarded more as a compensatory strategy to overcome the effects of the disorder rather than being part of the disorder itself [9]. Also, there is a distinct relationship between the numbers of letters in a word, and the time it takes to read it; the longer the word, the longer the completion time.

Pure alexia poses an interesting challenge for cognitive rehabilitation. Most likely, it is the result of damage to the functional processing of letters [10], a very particular sort of visual stimuli invented by humans themselves to represent the spoken word. Although reading may rely on other processes of identification of visual stimuli, letter and word reading is definitely an ability that humans have to acquire through intensive training.

The disorder of pure alexia may therefore be understood as either destruction of the learned algorithms of deciphering of visual letter input in which case there is a potential for relearning the destroyed knowledge. Alternatively, it may be a destruction in the subsequent 
layers of processing that is activated in the normal processing of visual stimuli in which case compensatory strategies may be of benefit [11].

\section{Rehabilitation of pure alexia}

Most of the current research effort within pure alexia has been invested into understanding how normal reading ability is acquired from studying the effects of damage. There are only a limited number of studies into actual rehabilitation of pure alexia. It seems that in many of the existing studies of pure alexia rehabilitation, it can even be questioned whether the subjects described actually had pure alexia [12]. Kinaesthetic training in which the patients learn to draw the letter in the hand supposedly to provide an alternative means of letter input showed improved generalized effect of reading for patients with severe alexia and a deficit in letter recognition [13,14], while multiple oral re-reading techniques has shown some potential for improving reading in more mildly affected patients. A comprehensive overview of Alexia treatment can be found in $[8,12]$.

\section{Method}

\section{The case}

The patient (NN) was 50 years old, right-handed male, with a doctorate in medicine. Prior to the injury been an avid reader of advanced technical and scientific literature.

After a flight home from New York, he suffers a pulmonary embolism. The subsequent thrombolysis-treatment for the emboli treatment led to a cerebral haemorrhage affecting his posterior left hemisphere. This was followed by a medullar haemorrhage causing a right-side paresis as well as a left side paresis of the lower extremities and a haematoma that subsequently had to be evacuated.

The initial ophthalmological assessment indicates no visual problems, but later assessments establish that the patient has an upper right quadrantanopia with a 2.2 degree sparing of foveal vision. Following the incident, the patient is no longer able to read normally. No other cognitive areas seemed severely affected and the patient was highly motivated to work towards reacquiring enough reading ability to return to work.

According to NN's medical records, neuropsychological assessment two months post injury revealed slow but correct reading of single words, while a few errors on word endings were noted in text reading. Writing of sentences, regular and irregular words, and non-words were without errors. No problems were noted in naming to spelling. Slight problems with naming of line drawings were noted (Boston naming task: 49/60), as well as problems with fragmented visual material (Street completion test: 5/20). The neuropsychological records state that information uptake was reduced in the right visual field.

NN started a rehabilitation programme at CRBI (Center for the Rehabilitation of Brain Injury, Copenhagen) 9 months after his injury.

Further details on the patient's reading, object recognition, and visual attention has been studied in detail and is reported in Starrfelt, Habekost, \& Gerlach [9] along with neuropsychological background data.

\section{Instructors}

Two people performed the actual training: 1) the principal investigator (the author), who conducted training and also supervised several training sessions to ensure commonality in training, 2) the patient's speech and language therapist, who was responsible for the planning of the overall training and therapy sessions for this patient. Both instructors shared the responsibility of developing and adapting the training material before and during the training.

\section{Place of training}

The training was conducted at CRBI on a daily basis in the office of the therapist. After the first two sessions, we noticed that the patient was distracted by too much clutter in the immediate vicinity of the patient's view of focus and that this was interfering with reading. We therefore cleared the table and walls of all but the necessary training material including the stopwatch to avoid sensory overload.

\section{Ethical considerations}

The patient was given oral as well as written information about the study prior to initiating the actual practice. The patient was fully informed about the novel and experimental nature of the training and that his performance would be subject to further scientific analysis and later publication. He was also instructed that he could request termination and leave the training at any point without repercussions. The patient gave his written consent to the use of the material for subsequent publishing. The study was approved by the local ethical committee at CRBI.

\section{Training schedule}

The patients trained for 5 days a week for three consecutive weeks. Each day the patient would train 45 minutes, then have a 15 minute break and then continue training for another 45 minutes. In addition, he was allowed small breaks when the need occurred to avoid fatigue.

\section{Daily session}

Each training day began and ended with the patient filling out a small questionnaire to qualitatively assess fatigue, motivation, physical health state, cognitive health state and emotional state. Following the daily training, the patient would rate the difficulty in training material presented during training. The purpose was to monitor aspects besides the training that might affect the progress of the patient.

After filling out the questionnaire, the patients were tested with the alphabet test (for more details, see below). A typical training session would then begin by reading 2-3 pages of words or non-words, followed by 3-4 pages of sentences. At the end of a training session, a text would be presented, read and checked for comprehension. All sessions with the patient were videotaped for later reference. All reading activity was timed and the results marked down on the instructor's copy of the training material.

\section{Training material}

Table 1 provides an overview of the training material and when it was used. Samples of the training material can be found in appendix A and the full collection is available at request from the author. 


\begin{tabular}{|c|c|c|c|c|c|c|c|c|c|c|c|c|c|c|c|}
\hline Training type/Day & 1 & 2 & 3 & 4 & 5 & 6 & 7 & 8 & 9 & 10 & 11 & 12 & 13 & 14 & 15 \\
\hline High frequency single words $1-2$ syllables & $\mathrm{x}$ & $\mathrm{x}_{1}$ & & & & & & & & & & & & & \\
\hline Single words $1-6$ syllables & & & & $x$ & & & & & & & & & & & \\
\hline Single word $1-4$ syllables low frequency & & & & & $x$ & & & & & & & & & $\mathrm{x}$ & \\
\hline Nonsense words 2 syllables & & & & & & & & $x$ & & & & & & & \\
\hline Nonsense 8 syllable words & & & & & & & & & $\mathrm{x}$ & $\mathrm{x}$ & $\mathrm{x}$ & & $\mathrm{x}$ & & \\
\hline High frequency 2-word sentences & $x$ & & & & & & & & & $x$ & & & & & \\
\hline Low frequency, high difficulty single words & & & & & & $x$ & $\mathrm{x}$ & $x$ & $\mathrm{x}$ & & & & & & \\
\hline $\begin{array}{l}\text { Three word sentences, high frequency verb } \\
\text { comprehension }\end{array}$ & $\mathrm{x}$ & & & & & & & & & & & & & & \\
\hline $\begin{array}{l}\text { Five word sentences, hHigh frequency words } \\
\text { relationship }\end{array}$ & $\mathrm{x}$ & $\mathrm{x}$ & $\mathrm{x}$ & & & $\mathrm{x}_{2}$ & $x_{3}$ & $\mathrm{x}_{4}$ & & & & & & & \\
\hline 3-14 word sentences & & & & $x$ & $x$ & & & $x_{5}$ & $\mathrm{x}_{6}$ & $x$ & & & & & $x_{1}$ \\
\hline Nonsense sentences mixed with real sentences & & & & & & & & & & & $x$ & & & & \\
\hline $\begin{array}{l}\text { Reading Oliver Sacks "The Man who mistook his wife } \\
\text { for a hat" }\end{array}$ & $\mathrm{x}$ & & & & & & & & & & & & & & \\
\hline Tekst with large font size & & $\mathrm{x}$ & $\mathrm{x}$ & & & & & & & & & & & & \\
\hline Text with Font size 12 & & $\mathrm{x}$ & & $\mathrm{x}$ & $\mathrm{x}$ & & & & & & & & & & $x$ \\
\hline "Dyret i dit spejl" semi scientific text, font size 14 & & & & & & $\mathrm{x}$ & $x$ & & $x$ & & & & & $\mathrm{x}$ & \\
\hline Scientific text & & & $x$ & & & & & & & & & & & & \\
\hline Regular text in english, normal font size & & & & & & & & & $\mathrm{x}$ & & & & $\mathrm{x}$ & & \\
\hline Medical journal & & & & & & & & & & $\mathrm{x}$ & $x$ & $\mathrm{x}$ & $\mathrm{x}$ & & \\
\hline Numbers & & & & & & & & $x$ & $\mathrm{x}$ & & & & & & \\
\hline Scanning for odd letter & & & & & & & & & & & & $x$ & & & \\
\hline Scanning for odd word left/right & & & & & & & & & & & & $\mathrm{x}$ & & & \\
\hline
\end{tabular}

Table 1: The training content. $\mathrm{x}_{1}$ With smaller font size, $\mathrm{x}_{2}$ Right justified text, $\mathrm{x}_{3}$ Left, right justified and upside -down, $\mathrm{x}_{4}$ Different font types, $\mathrm{x}_{5}$ In upper case, lower case, left and right justified, $\mathrm{x}_{6}$ Left, mid and right justified.

The training material was developed in a manner that allowed regulation of level of difficulty in accordance with progress inspired by the constraint induced language training done by Pulvermüller et al [6] and Meinzer and his team [15].

The training material consisted of A4-sheets which had content consisting of one of the following:

- Letters

- Words

- Non-words

- Single short sentences (positioned left, middle or right alignment)

- Single long sentences

- Pieces of text

During the course of training, the level of difficulty would be increased by varying almost all parameters available, one by one. For letters, we would change the size, colour, orientation and font. For words we would change the no of characters, the number of syllables, the frequency of words used (common or rarely used words), word similarities, combinations of letters that have similar features like b, $d$, p, q. Sentences would be presented in normal layout or with or without punctuation or all upper or lower case. For texts, we would vary the so-called readability index from easy texts (from children's books) to medical journals. Because of NN's rapid progress in reading, we even at one point changed the language of the texts used from Danish to English.

\section{Assessments}

\section{Pre-training assessment}

The reading ability of the patient was assessed by two independent professionals with two different tests prior to the start of the threeweek training period. In the first test, $\mathrm{NN}$ was tested with a computerized word length effect test at the Dept. of Psychology, University of Copenhagen. In the test, the subject sat in front of a 
computer screen. A black word would be displayed on a white background at the center of the screen in 36 point Times New Roman. The subject was asked to respond orally as fast as possible after onset. Response time was measured from word onset until oral response using a voice response key. Errors were recorded by an external assistant. Words were presented with a 2 second interval from the previous response and $\mathrm{NN}$ was instructed to read the words as fast and correctly as possible. NN practiced with 25 words before the actual test with another 25 words which varied from 3,5 or 7 letters and also in word frequency. Two similar post training tests were conducted to measure improvements in reading time at word level: the A test, which contained the same words as the pre-test and the B test which were matched in word length and difficulty but contained a different set of words.

The second test, the Danish adult reading and comprehension test, was performed by the resident reading specialist at the CRBI with two different pieces of text of similar difficulty before and after the training period. The reading test was a standard Danish adult reading test (Voksenpædagogisk grundprøve, [16]) used in the assessment of basic reading ability in adults. The test is a story about a person who ends up in a loyalty conflict and has to choose between two actions. The test must be read out load and afterwards, the subject must complete the story in writing and answer question to demonstrate comprehension.

A third test measuring reading speed and accuracy was performed the first and last day of the training. The speed was measured on single words, simple sentences and a text matched on word difficulty.

\section{During training assessment: The alphabet test}

This purpose of this test was to monitor progress in speed of reading at a daily basis which would be easily conveyed to the patient and serve as a motivational factor. We used two decks of cards with the 28 different letters (of the Danish alphabet) in upper (deck 1) and lower case (deck 2). The font size was similar for both decks of letters. One at a time the decks were shuffled and laid out on the table in a $7 \times 4$ grid, so the sequence of the letters was different each day. The patient was then asked to read out loud the letters as fast as possible.

\section{Post-training assessment}

After the conclusion of the three-week training period, the word length effect and reading test were repeated. The material used in both the tests were new but of similar level of difficulty to avoid unintentional training effects.

\section{Results}

\section{The first-last day reading test}

The results from the pre- and post-trial reading tests revealed an improvement in the reading performance when measured as number of standardized words read per minute. The conversion to standardized words has been done according to the MacKenzie standard [17] where number of letters and symbols are counted in a text (excluding blanks) and the result divided by 5 . This way, texts of similar level of difficulty, can be compared.

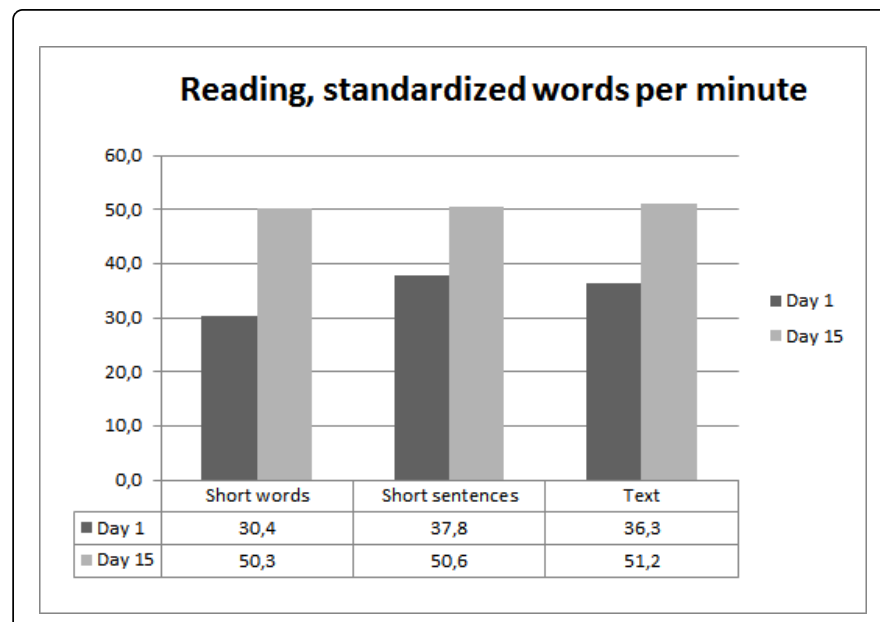

Figure 1: The improvement in words read per minute under three different conditions: simple word, simple sentences and standard text. MacKenzie standardization [17] has been used to convert the conditions to words per minute.

The measurements before and after training indicates a $65 \%$ improvement in reading speed of short words, $34 \%$ improvement for simple sentences and $41 \%$ for standard text.

\section{The Danish adult reading and comprehension test}

Before training, NN read the text very slowly (7min 18sek) with many mistakes (pauses, missed ending, repetition of words and sentences, semantic guessing and wrong identification of letters with similar characteristics). For comparison, the normal speed of reading this particular text is approximately 2 minutes.

After training, the measurements showed an improvement in both reading speed (25\%) and a reduction in mistakes (51\%).

\section{The alphabet test}

The daily results in milliseconds have been plotted in figure 2. A linear regression test suggests a negative relationship between the number of days trained (the independent variable) and the alphabet reading time for small letters $(\mathrm{alfa}=667.03, \mathrm{~B}=-16.39)$ and for large letters ( $\mathrm{alfa}=526.93, \mathrm{~B}=-8.76)$. There was a highly significant correlation between the number of days trained and small letter reading ( $\mathrm{r}=-.77, \mathrm{DF}=10, \mathrm{p}<.007$ one-tailed) and a significant correlation for large letters $(\mathrm{r}=-.62, \mathrm{DF}=10, \mathrm{p}<.028$, one-tailed).

The improvement for letter reading after 3 weeks of training was $16.4 \%$ and $8.8 \%$ for capitals. 
Page 5 of 7

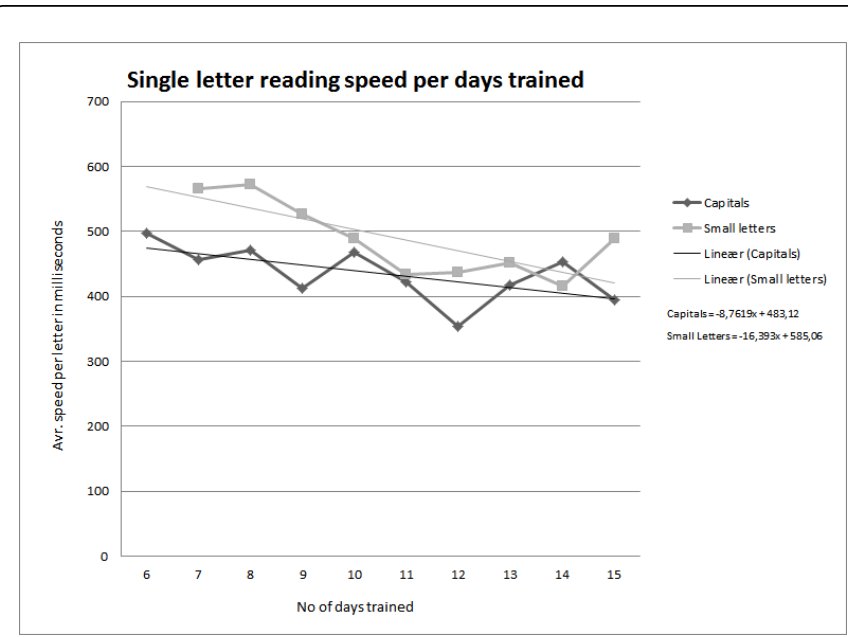

Figure 2: The average speed in milliseconds per letter based on results from reading 28 lower case letters (in lower case light grey line) and capitals (dark grey line).

\section{The computerized word length effect test}

In the analysis extreme outliers were removed from the data set. The difference in overall performance on the average response time in single word reading across word frequency and word length before $(\mathrm{M}=1870, \mathrm{SD}=1140)$ and after $(\mathrm{M}=1531, \mathrm{SD}=727)$ training was not significant for the same test $(\mathrm{A})(\mathrm{t}(21)=1.078$, two-tailed $\mathrm{p}=.293)$. It was also not significant for the B-test $(\mathrm{M}=1470, \mathrm{SD}=969)(\mathrm{t}(21)=1.118$, two-tailed $\mathrm{p}=.276$ ).

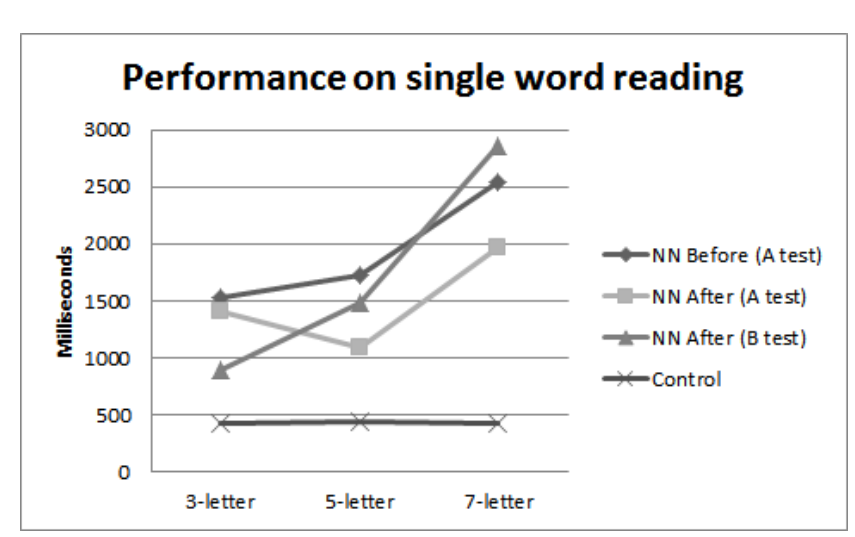

Figure 3: Performance on 3, 5 and 7 letter words compared to matching control. Lines show performance before and after the training period with a similar set of words (A) and a different but equally difficult set of words.

The test confirmed a word length effect normally associated with pure alexia. He read slowly but correctly at a rate that was approx. 4-6 times slower than comparable controls, with an increase in response times (word length effect) of $1006 \mathrm{~ms}$ (figure 3).

\section{Qualitative trial results}

The daily reports and the final interview with the patient revealed some interesting results. During the trials, the patient repeatedly mentioned that he felt invigorated and refreshed after each session. This was also observed by the instructors. The intensive and at times repetitive nature of the training did not seem to tire the patient at all. This is contrary to the normal experience at the CRBI where patients often experience fatigue during cognitive training.

The patient also reported increased confidence related to reading and writing and was fairly quickly able to follow subtitles on foreign language programs on TV. At the end of the training period, he was able to read newspapers, magazines and books and he ventured into given short oral presentations. After completing the entire 2 months of rehabilitation program at the Center for Rehabilitation of Brain Injury, he was able to read sufficiently well to return to a part-time medical position.

\section{Discussion}

The training in this study was aimed at improving general reading skills by practicing reading of letters, words and text presented under many different variations in letter size, word complexity, word length and even font type and colour. The training was provided on a daily basis for two hours over a period of three weeks, a combined practice length of 30 hours.

The results from the word length effect test showed the typical patterns for pure alexia in the processing of letters. The reaction time increased with the length of the word (figure 3 ) both pre- and posttraining. The average reading time for the 3,5 and 7 letter words were considerably higher than the comparable results from the healthy control and puts NN into the category of subjects with moderate word length effect [8]. However, there was no measurable improvement in the response time for single word reading before and after training.

Contrary to this, the reading tests indicate that the training had a positive effect on the generalized reading ability of the subject NN.

So the results conflict and lend credence to the theory that reading words and reading sentences engage different areas of comprehension which may be optimized individually. It does not confirm that the word letter effect may in itself be a compensatory strategy but it does suggest that improvement may be obtained in reading at a different level. One area might be in the oculomotor system. Studies have demonstrated a connection between the training of eye movements with optokinetic stimulation improved reading in patients with neglect alexia $[18,19]$. Unfortunately, we did not track eye movements during the practice so further investigation is needed.

All the reading tests were executed using material that was not used during training, so the results may be viewed as a generalized effect of the specific training. The only reused material was the daily letter test, but even here the letters were laid out in a random sequence every day.

The appropriate level of difficulty in the daily training was determined solely by the therapists and mostly based on direct observation and local measurements of speed. However, it may be argued that this is a critical point which has to be investigated further. The variation in training is critical for the improvements to generalize to other areas than just the trained material $[8,21]$.

It is currently unknown what exactly is improving when training this intensively with progressively more difficult material. Generally, 
Page 6 of 7

improvements from intensive training seem to arise from improvement in processing speed of external stimuli. This has been observed in several unrelated studies of cognitive training [21-23]. Most likely, some of the effects observed in our study would be the result of basic improvement of processing speed in the transmission of signals between the areas of visual processing. Further studies will have to be made to investigate which areas.

In addition, we have no way of knowing what the actual limit for the rehabilitation would be since there was no indication of performance levelling out as we reached the end of the planned training period.

The study has its limitations as it was done as part of the clinical rehabilitation treatment at the Center for Rehabilitation of Brain injury. The fact that there are no follow-up measurements is a weakness and inarguably limits the usefulness of the results in clinical practice. However, in light of the very few intervention studies done within pure alexia, we find that it is worth publishing to encourage further studies into the effects of intensive training.

\section{Lessons learned from the case}

The case study demonstrated in our view the following important points regarding the planning and execution of effect studies in cognitive rehabilitation. Firstly, with pure alexia, it is important to establish the differences in response performance across the patient's visual field in addition to a thorough perimeter test to detect deviation in the visual field. Also subtle difference in reaction time in visual processing between the two hemispheres may reveal latent symptoms of neglect in patients which may contribute to the observed reading difficulties. Secondly, eye tracking will be essential to test improvements in the oculomotor system in particular saccadic precision and latency. Thirdly, to ascertain progress and to ensure that the patient is challenged by the training it is necessary to monitor progress during training. Computerized tests with instant scoring are preferable to reduce the workload and to facilitate adjustments. In our study, we added the alphabet test to monitor progress and it turned out to be a good indicator of progress not only for the instructors but also for the patient. Additionally, the alphabet test turned out to be a visual and fast way to show progress important for the patient. The daily high score results from the alphabet test was highly motivating to the patient who was very keen on getting status reports on progress.

Lastly, in the future, the training material should be further structured and computerized where possible to reduce workload and to ease registration of results and to facilitate faster changes and updates.

\section{Conclusion}

The case study showed that intensive training has an effect on the reading skills of a person with acquired alexia. The improvements made by the training in this study seems to have improved sentence and letter reading speed but had no effect on single words.

Although reading ability never reached the premorbid level, the recovery was sufficient for the patient to return to work, give speeches and read more than before training.

The case study provided valuable research experience into intensive training methods for alexia and encourages further research into ways of ameliorating effects of brain injury.

\section{Declaration of interest}

The author was not affiliated with any organization or people in a financial or personal manner that might bias the results.

\section{Appendix A: Sample training material}

Copies of the complete training material are available from the author. The following are only small samples of the large collection of Danish material.

Words:

$\begin{array}{llll}\text { an anni } & \text { ananas } & \text { analyse } \\ \text { bo bade } & \text { balletsko } & \text { barmhjertighed } \\ \text { ca cirkus } & \text { checkhæfte } & \text { cykellygte }\end{array}$

Non-words:

ælle bong tvis klav

tribang kvivi lamså tæplo

olti abito tromo harot

Sentences:

vejen er glat i dag

jeg bor i en stor by

vil du have et glas vand

han troede at han kunne gå på vandet

Texts:

Extracts from the following books were used. In each case the extracts were matched in length and difficulty:

"Dyret i mit spejl" by Bent Jørgensen

"Manden der forvekslede sin kone med sin hat" by Oliver Sacks

"Snøvsen" by Benny Andersen

" The New Choice for sjette - Reader" by Jeremy Watts; Erik Larsen

Anonymized patient logs from CRBI.

\section{References}

1. Lacey EH, Lott SN, Snider SF, Sperling A, Friedman RB (2010) Multiple Oral Re-reading treatment for alexia: The parts may be greater than the whole. Neuropsychological Rehabilitation 20: 601-623.

2. Moyer SB (1979) Rehabilitation of Alexia: A Case Study. Cortex 15:139-144.

3. Behrmann M, Shallice T (1995) Pure alexia: A nonspatial visual disorder affecting letter activation. Cognitive Neuropsychology 12: 409-454.

4. Maher LM, Clayton MC, Barrett AM, Schober-Peterson D, Rothi LJG (1998) Rehabilitation of a case of pure alexia: Exploiting residual abilities. Journal of the International Neuropsychological Society 4: 636-647.

5. Meinzer M, Elbert T, Djundja D, Taub E, Rockstroh B (2007) Extending the Constraint-Induced Movement Therapy (CIMT) approach to cognitive functions: Constraint-Induced Aphasia Therapy (CIAT) of chronic aphasia. NeuroRehabilitation 22:311-318.

6. Pulvermuller F, Neininger B, Elbert T, Mohr B, Rockstroh B, Koebbel P, et al., (2001) Constraint-Induced Therapy of Chronic Aphasia After Stroke. Stroke 2001 32:1621-1626.

7. Pulvermüller F, Berthier ML (2008) Aphasia therapy on a neuroscience basis. Aphasiology 22:563-599. 
Citation: Wilms I L (2015) Case Study into the Effect of Intensive Mass Training on Chronic Pure Alexia. Int J Neurorehabilitation 2: 1000162. doi:10.4172/2376-0281.1000162

Page 7 of 7

8. Leff A, Starrfelt R (2014) Alexia : Diagnosis, Treatment and Theory. London: Springer London.

9. Starrfelt R, Habekost T, Gerlach C (2010) Visual processing in pure alexia: A case study. Cortex 46:242-255.

10. Behrmann M, McLeod J (1995) Rehabilitation for pure alexia - Efficacy of therapy and implications for models of normal word recognition. Neuropsychological Rehabilitation 5: 149-180.

11. Damasio AR, DamasioH (1983) The anatomic basis of pure alexia. Neurology 33:1573-1573.

12. Starrfelt R, Ólafsdóttir RR, Arendt IM (2013) Rehabilitation of pure alexia: A review. Neuropsychological Rehabilitation 23:755-779.

13. Lott SN, Friedman RB, Linebaugh CW (1994) Rationale and efficacy of a tactile-kinaesthetic treatment for alexia. Aphasiology 8: 181-195.

14. Maher LM, Clayton MC, Barrett AM, Schober-Peterson D, Rothi LJG (1998) Rehabilitation of a case of pure alexia: Exploiting residual abilities. Journal of the International Neuropsychological Society, 4: 636-647.

15. Meinzer M (2004) Neuropsychologische und Neurophysiologische Aspekte intensiver Sprachtherapie bei chronischer Aphasie. (Doktor der Naturwissenschaften), Universität Konstanz, Konstanz.

16. Christensen F, Hovgesen G (1996) Voksenpædagogisk Grundprøver Dansk psykologisk Forlag.

17. MacKenzie IS (2002) KSPC (Keystrokes per Character) as a Characteristic of Text Entry Techniques. In: Human Computer
Interaction with Mobile Devices, Paternò F (Ed.), 241: 195-210, Springer Berlin Heidelberg.

18. Kerkhoff G, Keller I, Ritter V, Marquardt C (2006) Repetitive optokinetic stimulation induces lasting recovery from visual neglect. Restorative Neurology and Neuroscience 24: 357-369.

19. Kerkhoff G, Schenk T (2012) Rehabilitation of neglect: An update. Neuropsychologia 50: 1072-1079.

20. Kleim JA, Jones TA (2008) Principles of experience-dependent neural plasticity: Implications for rehabilitation after brain damage. Journal of Speech Language and Hearing Research 51:S225-S239.

21. Finkel D, Reynolds CA, McArdle JJ, Pedersen NL (2007) Age changes in processing speed as a leading indicator of cognitive aging. Psychology and Aging 22: 558.

22. Mazer BL, Sofer S, Korner-Bitensky N, Gelinas I, Hanley J, et al., (2003) Effectiveness of a visual attention retraining program on the driving performance of clients with stroke. Archives of Physical Medicine and Rehabilitation 84:541-550.

23. Takeuchi H, Taki Y, Hashizume H, Sassa Y, Nagase T, et al., (2011) Effects of training of processing speed on neural systems. The Journal of neuroscience 31: 12139-12148. 